\title{
A praticabilidade de respostas administrati- vas em estado de necessidade no contexto da pandemia COVID-19
}

\author{
https://doi.org/10.21814/uminho.ed.25.3
}

\section{Carlos Abreu Amorim}

Carlos Abreu Amorim é Professor de Direito Administrativo e Direito do Ambiente na Escola de Direito da Universidade do Minho. Licenciado em Direito pela Universidade Lusíada é Mestre em Direito pela Universidade de Coimbra e Doutor em Direito pela Universidade do Minho. Foi Deputado da Assembleia da República (2011-2019) e Vice-presidente do Grupo Parlamentar do PSD, entre 2011 e 2017, com as responsabilidades do Poder Local e Ambiente, entre 2011 e 2014 e da Justiça e Administração Interna, entre 2014 e 2017. 


\section{A EVOLUÇÃo dA ESTRATÉGIA DOS PODERES PÚBLICOS FACE À SUBSISTÊNCIA DO PERIGO SANITÁRIO (COVID-19) - ESTADO DE EMERGÊNCIA, SITUAÇÃO DE CALAMIDADE, DE CONTINGÊNCIA E DE ALERTA}

Perante a ameaça crescente provocada pela pandemia de um coronavírus (SARS-COV-2), que origina uma doença (COVID-19), inusitadamente contagiosa e o receio de insustentabilidade do Serviço Nacional de Saúde (SNS) face à provável proliferação de doentes infetados, a 13 de março de 2020 o Governo elaborou o Despacho no 3298-B/2020 que emitiu a declaração de alerta em todo o território nacional ${ }^{1}$.

Contudo, os poderes conferidos às autoridades não foram considerados suficientes para fazer face à calamidade pública iminente, já então percecionada noutros países da União Europeia e, em conformidade, o Senhor Presidente da República através do Decreto no 14-A/2020, de 18 de março, declarou o estado de emergência. Esta declaração, por imperativo constitucional e legal, tem a limitação temporal de 15 dias $^{2}$. Foi, seguidamente, renovada pelo Decreto do Presidente da República no 17-A/2020, de 2 de abril, tendo sido objeto de segunda renovação mediante o Decreto do Presidente da República no 20-A/2020, de 17 de abril, que prolongou a vigência do estado de emergência até às 23:59 h do dia 2 de maio.

No final de abril, quando se tornou claro que o SNS permanecia apto a fornecer respostas de qualidade e que o número de contágios em Portugal não tinha revelado o dramatismo observado em alguns países europeus, a par das preocupaçóes permanentes com os efeitos de saúde pública da pandemia, a atenção dos poderes públicos centrou-se nas consequências económicas do confinamento e do encerramento de muitas atividades. Progressivamente, perspetivaram-se cenários muito negativos, de clara recessão

\footnotetext{
1 Publicado em Diário da República (DR) no 52/2020, 1o Suplemento, Série II, no 52/2020, de 13 de março. 2 De acordo com o disposto na Constituição da República Portuguesa (CRP), artigo 19, no 5. No mesmo sentido, essa limitação temporal está legalmente definida no artigo 5o, no 1, da Lei no 44/86, de 30 de setembro (Regime do Estado de Sítio e do Estado de Emergência): "O estado de sítio ou o estado de emergência terão duração limitada ao necessário à salvaguarda dos direitos e interesses que visam proteger e ao restabelecimento da normalidade, não podendo prolongar-se por mais de 15 dias, sem prejuízo de eventual renovação por um ou mais períodos, com igual limite, no caso de subsistência das suas causas determinantes”.
} 
económica, que iriam atingir a generalidade das economias europeias e mundiais. Tentando evitar a ocorrência desses panoramas mais prejudiciais, as autoridades nacionais elaboraram planos de desconfinamento gradual, procedendo à abertura progressiva de algumas atividades económicas, mas, sublinhe-se, nunca perdendo o acento tónico nas políticas e açôes administrativas relacionadas com a prevenção dos contágios. A ideia assumida pelos poderes públicos passou, também, a integrar uma lógica de desconfinamento sob a égide dos princípios da prioridade, da prevenção, da precaução, da subsidiariedade, da cooperação, da coordenação, da unidade do comando e da informação, todos constantes da Lei de Bases da Proteção Civil ${ }^{3}$ e claramente demonstrativos da lógica das respostas excecionais e urgentes que a situação de calamidade, ulteriormente decretada, considera e pressupóe.

Tal como sucedia durante a vigência do estado de emergência, na situação de calamidade continuou-se a tentar evitar as hipóteses de contágio, criando um quadro muito acentuado de prudência quanto ao comportamento dos cidadãos e à vigilância das entidades públicas, com o intuito de que não se perdesse tudo o que de positivo para a saúde pública e, designadamente, para as boas respostas do SNS, que fora adquirido com os sacrifícios a que os cidadãos portugueses foram sujeitos desde os idos de março de 2020. Este propósito de prudente e gradual reabertura de certas atividades, designadamente no plano económico, deixaria de estar sob a cobertura do quadro constitucional e legal do estado de emergência. Contudo, tal plano seria possível de implementar através de uma declaração de situação de calamidade, por iniciativa do Governo, mas com o acordo expresso do Senhor Presidente da República e o assentimento dos partidos políticos representados na Assembleia da República.

Consequentemente, a partir do dia 3 de maio de 2020, Portugal entrou em situação de calamidade, decretada pelo Governo, através da Resolução do Conselho de Ministros no 33-A/2020, de 30 de abril, que vigorou até às 23:59h do dia 17 de maio de $2020^{4}$. A situação de calamidade foi prorrogada a 17 de maio através da Resolução do Conselho de Ministros no 38/2020, o mesmo acontecendo a 29 de maio com a

3 Estes princípios estão presentes no artigo 5o da Lei no 27/2006, de 3 de julho, com as alteraçôes da Lei no 80/2015, de 3 de agosto.

4 De acordo com o no 1 da mesma Resolução do Conselho de Ministros. 
Resolução do Conselho de Ministros no 40-A/2020, e, também, veio a ser novamente prorrogada pela Resolução do Conselho de Ministros no 43-B/2020, de 12 de junho. Logo a 30 de abril, o plano de desconfinamento, ao abrigo da lógica do estado administrativo excecional que é a situação de calamidade, cujo conceito adiante desenvolveremos, foi desenhado em três fases, a primeira iniciada no final do estado de emergência, a 3 de maio, uma outra que se iniciou a 18 de maio e outra, ainda, prevista no final do mês de maio de $2020^{5}$.

Porém, o desconfinamento gizado em maio e junho não obteve os resultados desejados de modo territorialmente uniforme. O número de novos casos de infetados pareceu descer significativamente em quase todo o território nacional, bem como nos arquipélagos da Madeira e dos Açores. Todavia, na região de Lisboa e Vale do Tejo (LVT) o nível de contágio começou a subir desde o final de maio, revelando focos de novos infetados muito preocupantes nos municípios limítrofes de Lisboa e, inclusivamente, em algumas freguesias da própria capital do país. Esses efeitos imprevistos e indesejados do desconfinamento, territorialmente desequilibrados, forçaram a uma mudança de estratégia por parte do Governo. Assim, em 25 de junho de 2020, o Conselho de Ministros emitiu um Comunicado ${ }^{6}$ em que se definiam para o futuro e a partir do dia 1 de julho, face aos diferentes estágios da evolução da pandemia nas várias áreas geográficas do país, três situações distintas com níveis diferenciados de respostas administrativas, designadamente a situação de alerta, de contingência e de calamidade:

5 Cfr. número 2 da Resolução do Conselho de Ministros no 33 -C/2020, de 30 de abril.

6 Comunicado do Conselho de Ministros de 25 de junho de 2020, consultado em https://www.portugal.gov. $\mathrm{pt} / \mathrm{pt} / \mathrm{gc} 22 /$ governo/comunicado-de-conselho-de-ministros?i=354. 
«O Conselho de Ministros aprovou hoje a resolução que dá continuidade ao processo de desconfinamento iniciado a 30 de abril ${ }^{7}$, declarando a situação de alerta, contingência e calamidade, consoante o território, com efeito a partir das 00:00h do dia 1 de julho e até 23:59h do dia 14 de julho de 2020».

A ideia patente seria a de que os diferentes resultados da evolução do nível contágios obrigavam a respostas públicas separadas dentro e fora da região de LVT e, também, no interior desta. Deste modo, foi criado uma espécie de "zonamento sanitário" dentro da região mais atingida pelos novos contágios mediante a Resolução do Conselho de Ministros no 51-A/2020, de 26 de junho, que determina a situação de calamidade em seis freguesias do concelho da Amadora, quatro do concelho de Odivelas, uma do concelho de Lisboa, três do concelho de Loures e quatro do concelho de Sintra ${ }^{8}$. Com a exceção desses municípios e freguesias sujeitos à situação de calamidade, toda a Área Metropolitana de Lisboa ficou sob situação de contingência'? E, salvaguardando os municípios e freguesias submetidas a situação de calamidade e de contingência, todo o território nacional continental passou a estar sujeito a situação de alerta $^{10}$.

O Governo parecia não ter dúvidas acerca das razões que fizeram vacilar a estratégia de desconfinamento na região da capital. $\mathrm{Na}$ exposição de motivos do Decreto-Lei no 28-B/2020, de 26 de junho, que agrava o regime contraordenacional para os

\footnotetext{
7 Julgamos existir um lapso reiterado nesta data referenciada quer nas várias exposiçóes de motivos das Resoluções do Conselho de Ministros que prorrogaram a situação de calamidade quer no Comunicado do Conselho de Ministros de 25 de junho como aquela em que se deu o início do "desconfinamento". Conforme foi exposto supra, o estado de emergência só deixou de vigorar em todo o território nacional no dia 2 de maio de 2020. Provavelmente, a origem da confusão residirá na data da publicação da Resolução do Conselho de Ministros no 33-A/2020, de 30 de abril. Embora seja líquido que a data de um diploma é o da sua publicação, acontece que esta Resolução do Conselho de Ministros só iniciou a sua produção de efeitos no dia 3 de maio, tal como está expressamente estabelecido no ponto no 11 da própria: «... a presente resolução produz efeitos a partir das 00:00 b do dia 3 de maio de 2020». Para além do mais, o Decreto do Presidente da República no 20-A/2020, de 17 de abril, que procedeu à segunda renovação do estado de emergência afigura-se, também, inequívoco quando dispóe acerca do seu próprio tempo de vigência, no artigo 3: «A renovação do estado de emergência tem a duração de 15 dias, iniciando -se às 0:00 horas do dia 18 de abril de 2020 e cessando às 23:59 horas do dia 2 de maio de 2020». Donde, em rigor, o "desconfinamento" só se terá iniciado nessa data.

8 Cfr. número 1, alínea a), da Resolução do Conselho de Ministros no 51-A/2020, de 26 de junho.

9 Cfr. número 1, alínea b), idem.

10 Cfr. número 1, alínea c), ibidem.
} 
incumprimentos das determinaçóes dos poderes públicos decorrentes da pandemia, essas razões estão declaradas:

«Apesar da tendência atual de evolução da situação epidemiológica, verifica-se que os novos contágios decorrem, frequentemente, de situações de incumprimento das normas de distanciamento físico, em especial em eventos que implicam a aglomeração de pessoas. Torna-se necessário, portanto, associar o incumprimento das disposições que visam assegurar a adoção de práticas sociais adequadas à aplicação de sanções administrativas com efeito predominantemente dissuasor.» ${ }^{11}$

São estas as situações de excecionalidade, de natureza constitucional e administrativa, que vigoraram em Portugal durante o período temporal em que se enquadra a análise jurídica que nos propomos realizar.

\section{1 Do estado de emergência}

O estado de emergência corresponde a uma das respostas mais robustas dos órgãos de soberania a uma situação patente ou iminente de verificação de um perigo grave para a existência do Estado, a segurança e a organização da coletividade, que não podem ser eliminados pelos meios normais previstos na Constituição da República Portuguesa (CRP). Constitui uma situação constitucional excecional que é consequência direta de circunstâncias fácticas anormais e que solicita decisões e resoluções de natureza extraordinária por parte das autoridades que, em princípio, não poderão ser obtidas com a mesma eficácia mediante os mecanismos normais previstos na CRP e na lei ${ }^{12}$. Apesar de o estado de emergência ser menos intenso do que a outra resposta excecional consagrada na CRP, o estado de sítio $^{13}$, provoca uma suspensão parcial de direitos, liberdades e garantias, respeitando o princípio da proporcionalidade e na medida estritamente adequada e necessária ao pronto restabelecimento da normalidade.

\footnotetext{
11 Segundo e terceiro parágrafos da exposição de motivos do Decreto-Lei no 28-B/2020, de 26 de junho. 12 Cfr. Canotilho, J.J. Gomes, Moreira, Vital. (2007). Constituição da República Portuguesa Anotada (4o․ ed.), Coimbra: Coimbra Editora: 399-400.

13 Cfr. artigo 19, no 3, da CRP e artigo 9o, no 1, da Lei no 44/86, de 30 de setembro.
} 
A intenção primordial do estado de emergência que, concretamente, vigorou em Portugal entre os dias 18 de março e 2 de maio de 2020 foi prevenir a transmissão do vírus e conter a pandemia, dotando os poderes públicos de capacidades muito acrescidas que lhes permitiram aplicar medidas transitórias, extraordinárias e urgentes, de restrição de direitos e liberdades, designadamente no que respeita aos direitos de circulação e liberdades económicas sem correr o risco de ofender a CRP e a legalidade vigente ${ }^{14}$. Embora a sua inquestionável raridade o converta num mecanismo constitucional excecional não se trata de um instrumento extravagante que eventualmente colida com a CRP ${ }^{15}$. Não apenas por nela estar previsto, mas, sobretudo, porque a sua utilização obedece a regras estritas que a controlam, limitam e enquadram dentro da lógica constitucional. Como já foi defendido, estamos perante uma verdadeira garantia constitucional ${ }^{16}$. Ainda assim, a natureza marcadamente extraordinária deste mecanismo está espelhada na raridade da sua utilização, pois a sua declaração, em 18 março de 2020, foi pioneira nos 44 anos de vigência da atual lei fundamental ${ }^{17}$.

A declaração do estado de emergência, bem como, de modo mais definido, os termos e condiçóes precisos das várias concretizações governamentais ${ }^{18}$ dos Decretos presidenciais que proclamaram e prorrogaram o estado de emergência, convergem para uma limitação temporária dos direitos e liberdades de circulação, de encerramento de instalaçôes e estabelecimentos, de suspensão de atividades de comércio e de prestação

14 Intenções que subsistem de forme perene na situação de calamidade que se lhe seguiu como adiante analisaremos.

15 Miranda, Jorge, Medeiros, Rui (2005). Constituição Portuguesa Anotada, Tomo I, Coimbra: Coimbra Editora: 166 e ss.

16 Ramião, Ruben (2020). A Eficácia Retroativa do Estado de Emergência (resposta a Jorge Reis Novais) in ICP - CIDP, março de 2020 (disponível em: https://www.icjp.pt/sites/default/files/papers/a_eficacia_retroativa_do_estado_de_emergencia_resposta_a_jorge_reis_novais_0.pdf.

17 No regime democrático, uma declaração semelhante só tinha sido realizada em 25 de novembro de 1975, quando a CRP se encontrava ainda em fase de elaboração e meses antes da sua entrada em vigor, o que veio a acontecer em 25 de abril de 1976.

18 Decreto da Presidência do Conselho de Ministros no 2-A, de 20 de março; Decreto da Presidência do Conselho de Ministros no 2-B/2020, de 2 de abril; e Decreto da Presidência do Conselho de Ministros no 2-C/2020, de 17 de abril. Estes diplomas formam o núcleo essencial da resposta governamental à crise pandémica COVID-19, servindo de base e fundamento dos diversos instrumentos legislativos e regulamentares que integram a denominada Legislação COVID-19 - ver, infra, nota de rodapé no 20. 
de serviços, restriçốes de acesso, regras de higiene e segurança, entre outras reservas que se reconduzem a dever geral de recolhimento domiciliário e a deveres ainda mais adensados como o "dever especial de proteção" ou, até, o "confinamento obrigatório" para aqueles que se encontrarem específica e circunstanciadamente em situação de risco acrescido. A ideia clara do legislador, ajustada à lógica constitucional e legal que preside ao estado de emergência, foi proceder a uma limitação excecional de direitos que permita aos poderes públicos fazer face a uma ameaça iminente ou já em execução que se mostre capaz de colocar em perigo substancial a sociedade, as pessoas, a sua vida e a sua segurança, bem como a atuação do Estado enquanto protagonista principal na defesa dos valores essenciais que as conformam. O estado de emergência foi decretado com o intuito de que essa mesma restrição de direitos seja apta a facilitar e a possibilitar o seu pronto e eficaz restabelecimento. Ou seja, o seu fim primordial não é o imediato e aparente - a limitação de direitos é declarada com o desígnio claro de que estes possam ressurgir de forma mais rápida e robustecida ${ }^{19}$. No que tange aos efeitos precisos que resultaram das três declaraçóes do estado de emergência que Portugal conheceu entre meados de março e princípios de maio, estes traduzem-se em evitar o mais possível os contatos entre as pessoas, alterando as regras comuns de convivência, bem como, consequentemente, os modos comuns de laboração e de funcionamento daquelas atividades públicas e privadas em que o contato pessoal seja necessário ou que se tenha constituído como padrão de normalidade.

Numa simples interpretação declarativa dos vários diplomas do importante acervo legal e regulamentar a que se veio dar o nome de Legislação COVID-1920, torna-se inquestionável que a intenção primordial dos órgãos de soberania se centrou na limitação

19 Insistimos que, a nosso ver, este fim primordial do estado de emergência não se distingue das razóes que presidem à situação de calamidade como adiante analisaremos.

20 Denominação que passou a ser dada ao vasto manancial legislativo e regulamentar que foi gerado a partir das Declarações do estado de emergência do Senhor Presidente da República e dos diplomas governamentais que diretamente as concretizaram, bem como pela subsequente atividade legislativa e regulamentar do Governo e dos vários atos legislativos que a Assembleia da República elaborou no mesmo contexto e sentido. A Declaração governamental da situação de calamidade, de contingência e de alerta, assim como todo o acervo legislativo e regulamentar que se lhe seguiu integram-se neste mesmo conjunto. A Legislação COVID-19 pode ser encontrada de forma compilada e cronológica em: https://dre.pt/legislacao-COVID-19-upo. 
significativa dos contatos pessoais em quase todos os planos de atividade, seja nos atos de mera informalidade e confraternização, nas circunstâncias habituais de convívio nas relaçốes laborais, de amizade ou entre os familiares, incluindo os naturais e socialmente mais consistentes como são aqueles que decorrem das relações com os entes familiares mais idosos, quer, ainda, nos modos de exercício da generalidade das atividades profissionais que impliquem o contato ou o relacionamento próximo entre pessoas. Nesta última situação, conforme se verificará infra, enquadra-se integralmente o funcionamento dos órgãos da Administração Pública ${ }^{21}$. Em boa verdade, tal como está afirmado na exposição de motivos do Decreto no 2-B/2020, o propósito inequívoco do legislador é que os contatos entre as pessoas, bem como as suas deslocaçóes, devem manter-se «ao nivel minimo indispensável» enquanto os efeitos da pandemia COVID-19 persistirem no território português. E as razóes que presidem a estas precauções são inquestionáveis. A pandemia que, ainda hoje, assola o mundo inteiro caracteriza-se por essa vigorosa propensão para o contágio, muitas vezes assintomático, escondida do próprio portador do vírus que o pode propagar julgando-se livre de qualquer sinal de doença. O resultado, por todos conhecido, é a disseminação do vírus pelo planeta a uma velocidade vertiginosa, provocando medos globais, enclausurando atividades, fechando fronteiras e economias, alterando os modos comuns de funcionamento de quase todas as funções, designadamente aquelas que implicam o contato entre pessoas.

\subsection{Da situação de calamidade como um estado de quase-emergência}

A situação de calamidade constitui um estado administrativo de exceção caraterizado por um nível de acentuada vigilância administrativa visando dotar a Administração Pública dos meios e respostas necessárias para fazer face à iminência ou à verificação já efetiva de um perigo grave para prossecução de um fim de interesse público relevante ou, ainda, para permitir o funcionamento capaz da própria Administração em tempos de um quadro factual extraordinário. A situação de calamidade é conformada por circunstâncias incomuns que alteram a lógica da normalidade e tornam insuficientes as

21 Ver Coimbra, José Duarte, Caldeira, Marco, Serrão, Tiago (2020). Direito Administrativo da Emergência. Coimbra: Almedina: 17-36. 
respostas administrativas gizadas para momentos de constatação corrente e previsível dos factos. Tem como consequência a limitação de certos direitos das pessoas e das instituições públicas e privadas, designadamente quanto à liberdade de movimentação, de reunião, de relacionamento e de convívio pessoal. Essas restrições são fundamentadas e realizadas tendo sempre em vista a salvaguarda de um fim superior de interesse público que claramente se sobrepóe aos direitos e liberdades que possam ser objeto de coartações. Aliás, tal como acontecia no estado de emergência com quem a situação de calamidade mantém sobejas afinidades - não apenas nos motivos que lhes deram origem mas, também, nas soluçóes jurídicas e nos seus efeitos concretos quanto ao desenho dos deveres dos cidadãos.

A situação de calamidade, enquanto estado de exceção administrativo, é declarada pelo Governo com base nas suas competências administrativas definidas na CRP ${ }^{22} \mathrm{e}$ baseia-se na Lei de Bases da Proteção $\mathrm{Civil}^{23}$. Os poderes governamentais de natureza restritiva estão revigorados com a Lei relativa ao Sistema de Vigilância em Saúde Pública ${ }^{24}$, bem como muita da Legislação COVID-19 que permanece em vigor como o Decreto-Lei no 10-A/2020, de 13 de março e a Lei no 1-A/2020, de 19 de março ${ }^{25}$.

O sumário expositivo da Resolução do Conselho de Ministros no 33-A/2020, de 30 de abril, que decretou e definiu as condiçôes e os fundamentos da situação de calamidade é sumamente cristalino quanto aos seus fundamentos, natureza e efeitos, que vigoraram a partir do dia 3 de maio. Logo nos parágrafos iniciais é fixada a «situação excecional», assim como a indiscutível prioridade a precaver na presente situação de calamidade, exatamente a mesma que subsistia no estado de emergência «prioridade de prevenção da doença, contenção da pandemia e garantia da segurança dos portugueses» ${ }^{26}$.

22 Cfr. CRP, artigo no 199o, alínea g).

23 Lei no 27/2006, de 3 de julho, com as alteraçốes da Lei no 80/2015, de 3 de agosto. A declaração da situação de calamidade, está consagrada no artigo 8o, no 1, alínea c). O seu âmbito e limites, estão definidos nos artigos 19 a a 30, do mesmo diploma.

24 Lei no 81/2009, de 21 de agosto.

25 Essencial, também, para perceber o alcance da presente situação de calamidade é o Decreto-Lei no 20/2020, de 1 de maio.

26 Cfr. segundo parágrafo do sumário expositivo da Resolução do Conselho de Ministros no 33-A/2020, de 30 de abril. 
Continua o mesmo sumário expositivo da Resolução assinalando que as medidas de desconfinamento progressivo não obstam, pelo contrário, ao exercício contínuo da precaução no sentido de poder ser atingido o inequívoco propósito da situação de calamidade:

«Sucede, porém, que a avaliação efetuada pelas autoridades de saúde determina ser fundamental continuar a conter a transmissão do vírus para controlar a situação epidemiológica em Portugal $\gg^{27}$.

Este é o fito principal da situação de calamidade: realizar um «caminho de regresso gradual da atividade económica ao seu normal funcionamento ${ }^{28}$ mantendo muitas das restriçôes, suspensões e interdições, que matizaram o estado de emergência. Daí considerar-se $\left\langle\right.$ fundamental ${ }^{29}$ que as pessoas em risco especial, como são aquelas que se encontram doentes e as que estão em vigilância ativa, fiquem em confinamento obrigatório - o que, sublinhe-se, era precisamente o que já acontecia durante a vigência plena do estado de emergência, mediante a aplicação do disposto no artigo 3o, ㄲo 1, do Decreto oo 2-C/2020, de 17 de abril, que constituiu a concretização governamental da segunda renovação do estado de emergência decretada pelo Senhor Presidente da República. Também numa óbvia linha de continuidade entre o estado de emergência e a situação de calamidade se deve percecionar a regra geral de conduta nesses dois momentos de natureza excecional: o dever de recolhimento. Se durante a vigência do estado de emergência, que no seu último período foi materializado pelo Decreto no 2-C/2020, de 17 de abril, estabeleceu-se o "dever geral de recolhimento domiciliário" ${ }^{30}$ como regra de conduta para todos os cidadãos cuja idade e condiçôes específicas de saúde não implicassem o "confinamento

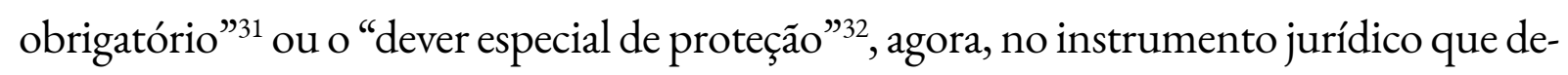
terminou a situação de calamidade, existe igualmente uma regra geral de comportamento de recolhimento domiciliário, desta vez trajado de "dever cívico" em vez de "dever geral":

27 Cfr. terceiro parágrafo, idem.

28 Cfr. segundo parágrafo, idem.

29 Cfr. oitavo parágrafo, idem; e ver artigo 2o, no 1 do Anexo a que se refere o oㅡ 2 da Resolução do Conselho de Ministros no 33-A/2020, de 30 de abril.

30 Ver artigo 5o, do Decreto no 2-C/2020, de 17 de abril.

31 Ver artigo 3o idem.

32 Ver artigo $4^{\circ}$, idem. 
«... a população deve procurar cumprir um dever cívico de recolhimento domiciliário, dando primazia às atividades, decisões e deslocações que não impliquem um contato social alargado ${ }^{33}$.

Em consequência, no Anexo dispositivo da mesma Resolução do Conselho de Ministros, no artigo 3o, sob a epígrafe «Dever civico de recolbimento obrigatório», é estabelecida a regra geral de conduta para todos os cidadãos ${ }^{34}$. Sucede que, não por acaso, a norma correspondente que vigorava durante o estado de emergência, o artigo 5o, do Decreto no 2-C/2020, de 17 de abril, possui uma redação intrinsecamente semelhante com esse artigo 3o, da Resolução do Conselho de Ministros no 33-A/2020, de 30 de abril, encontrando-se, entre os dois artigos, correspondências literais e de sentido lógico inquestionáveis:

i) Ambos equivalem à definição de regras gerais de comportamento dos cidadãos; ii) Ambos determinam o recolhimento domiciliário como situação-regra exceto nos casos de deslocações autorizadas e previstas nalgumas das circunstâncias descritas no mesmo artigo;

iii) Essas circunstâncias apenas parecem diferenciarem-se em questões de pormenor. Senão vejamos:

a. Todo o conteúdo dispositivo das alíneas a) até g), ii), inclusive, dos artigos respetivos, é integralmente idêntico;

b. A alínea h), do no 2, artigo 3o, da Resolução, refere a possibilidade de «Deslocaçóes a bibliotecas e arquivos, bem como a espaços verdes e ao ar livre em museus, monumentos, palácios e sitios arqueológicos ou similares» o que não acontecia com o o 1, do artigo 5o, do Decreto no 2-C/2020, porque esses serviços não estavam abertos ao público durante a vigência do estado de emergência;

c. As alíneas h) do no 1, do artigo 5, do Decreto no 2-C/2020 e e i) do no 2,

33 Cfr. nono parágrafo do sumário expositivo da Resolução do Conselho de Ministros no 33-A/2020, de 30 de abril.

$34 \mathrm{Na}$ concretização governamental do estado de emergência estão traçadas nas várias alíneas do no 1 , do artigo 5o, do Decreto no 2-C/2020, de 17 de abril. Na determinação da situação de calamidade as mesmas encontram-se nas alíneas do no 2, do artigo 3o da Resolução do Conselho de Ministros no 33-A/2020, de 30 de abril. 
artigo 3o, da Resolução, referem-se a atividades físicas, sendo que o caráter autorizativo da Resolução é mais alargado;

d. O mesmo sucede com o disposto nas alíneas j), k), do no 2, artigo 3o, da Resolução, abrangendo outras atividades físicas e de lazer;

e. As alíneas 1), m), n), do no 2, artigo 3o, da Resolução, são integralmente iguais ao disposto nas alíneas i), j), e k), do no 1 , do artigo 5o, do Decreto oㅡ 2-C/2020;

f. A alínea o), do no 2, artigo 3o, da Resolução e a alínea l), do no 1, do artigo 5o, do Decreto no 2-C/2020 possuem uma ligeira diferença literal mas são idênticas quanto ao sentido lógico;

g. O mesmo se pode dizer quanto às alíneas p), do no 2, artigo 3o, da Resolução e m), do no 1, do artigo 5o, do Decreto oㅡ 2-C/2020;

h. Por sua vez, o conteúdo das alíneas n) até u), do no 1 , do artigo 5o, do Decreto no 2-C/2020 é inteiramente o mesmo das alíneas q) até w), do no 2, artigo 3o, da Resolução;

i. Essa plena igualdade de redação verifica-se também entre os números 3, 4e 5, do artigo 3o, da Resolução, e os números 2, 3, e 4, do artigo 5o, do Decreto no 2-C/2020.

Conforme se manifesta, é intensa a semelhança dispositiva entre o instrumento jurídico que determinou a situação de calamidade a partir de dia 3 de maio e o decreto de concretização governamental da segunda renovação do estado de emergência. Não apenas nos artigos de que aqui fazemos a comparação concreta, mas em quase todas as demais disposiçôes normativas dos diplomas. Assim, a situação de calamidade que passou a vigorar em Portugal no dia 3 de maio manifesta-se como um prolongamento lógico do estado de emergência que subsistiu até essa data. Ambas são situaçôes de exceção que partilham os mesmos fins subjacentes à sua declaração, visam a salvaguarda dos mesmos bens jurídicos, máxime a saúde pública, obedecem aos mesmos princípios jurídicos conformadores, mormente os da prevenção, precaução e proporcionalidade e, ainda, ambas implicam um quadro de diminuição de direitos tendo por desígnio assumido o seu pronto restabelecimento mal as condições factuais de evolução positiva do combate à pandemia o permitam. 
Nesse sentido, muitas das lógicas de conduta exigidas aos cidadãos a que correspondem um quadro de deveres são análogos e de efeitos equivalentes. Obviamente que a situação de calamidade possui robustez jurídica inferior à do estado de emergência. Desde logo, por não possuir direta consagração constitucional e porque não está diretamente vocacionada para habilitar a diminuição drástica dos direitos, liberdade e garantias. Também, porque não é declarada pelo Presidente da República nem pressupóe a aprovação formal da Assembleia da República, nem antevê a possibilidade de intervenção das Forças Armadas. Contudo, ainda que assim seja, a situação de calamidade que produziu os seus efeitos a partir do dia 3 de maio tem semelhanças irrecusáveis com o estado de emergência que vigorou entre 18 de março e o dia 2 de maio de 2020.

Como expusemos supra, na análise dos diplomas jurídicos que a consagraram e definiram, perdura de forma indelével uma linha de continuidade lógica entre esses dois estados de exceção, um quase-cordão umbilical entre as duas situaçôes de excecionalidade, para além da diferença de suportes jurídicos formais que as distinguem, podendo-se depreender que a situação de calamidade decretada em Portugal corresponde a uma amenização do estado de emergência, um degrau inferior na gravidade e na excecionalidade que, mantendo um elevado grau de prevenção e de precaução e procurando prosseguir as mesmas finalidades de interesse público, visou permitir o levantamento prudente e gradual das restriçóes aos direitos dos cidadãos e criar condiçôes de reabertura progressiva das atividades económicas.

Enquanto estado administrativo de exceção pressupõe a existência de circunstâncias fácticas extraordinárias, incomuns, para cuja resposta, por parte da Administração Pública, não se adeque o chamado direito da normalidade. Ao invés, a necessidade de soluçôes peculiares implica que a Administração Pública se veja na contingência de encarar a produção de decisões num quadro de urgência permanente seguindo os ditames lógicos e modernos do princípio da legalidade que a melhor doutrina administrativista tem designado por princípio da juridicidade ${ }^{35}$, em que se sublinha a vinculação da Administração não apenas à lei mas, também, ao direito e

35 Ver Gonçalves, Pedro Costa (2019). Manual de Direito Administrativo, Vol. 1, Coimbra: Almedina: 184 ss. Ver, também, a ideia de insuficiências do princípio da legalidade em ALMEIDA, Mário Aroso de (2020). Teoria Geral do Direito Administrativo (6a). Coimbra: Almedina: 85. 
que se encontra plasmado no artigo 3o, no 1, e, também, no artigo 161o, no 2, alínea 1), do Código de Procedimento Administrativo (adiante CPA) ${ }^{36}$. Neste quadro geral de excecionalidade, comum ao estado de emergência e à situação de calamidade, os órgãos administrativos, muitas vezes, vêem-se forçados a atuar em estado de necessidade $^{37}$ procurando ressalvar as finalidades de interesse público relevante que se podem encontrar ameaçadas pelas circunstâncias excecionais ou, ainda, por atuaçóes de outros órgãos administrativos que, impavidamente, pretendam continuar a agir como se o contexto factual fosse de normalidade inabalável e o contexto de excecionalidade pudesse ser assumido como uma questão de mera opinião.

\subsection{Da excecionalidade mitigada dos estados de contingência e de alerta}

A partir das $00.00 \mathrm{~h}$ do dia 1 de julho de 2020 a Área Metropolitana de Lisboa passou a estar sujeita a estado de contingência, com exceção das freguesias às quais foi determinada a situação de calamidade ${ }^{38}$, enquanto que todo o restante território de Portugal continental ficou sob estado de alerta $^{39}$.

A situação de contingência ${ }^{40}$ está consagrada na alínea b), do no 1, do artigo 8o, da Lei de Bases da Proteção Civil. No mesmo artigo, no no 3, identifica-se uma relação de «subsidiariedade» entre os três patamares de exceção administrativos, calamidade, contingência e alerta, e a necessidade de, em regra, praticar previamente atos do estado

$36 \mathrm{CPA}$, artigo 3o, no 1: «Os órgãos da Administração Pública devem atuar em obediência à lei e ao direito, dentro dos limites dos poderes que lhes forem conferidos e em conformidade com os respetivos fins.»

37 Sintomaticamente, o artigo 23, no 2, da Lei de Bases da Proteção Civil, refere de forma expressa uma presunção legal nesse mesmo sentido: «Os atos jurídicos ou operaçôes materiais adotadas em execução da declaração de situação de calamidade para reagir contra os efeitos de acidente ou catástrofe presumem-se praticados em estado de necessidade» (sublinhado nosso).

38 Cfr. supra, notas de rodapé números 8 , 9 e 10.

39 Número 17, da Resolução do Conselho de Ministros no 51-A/2020, de 26 de junho.

40 Não foi a primeira vez que o estado de contingência foi decretado em Portugal na pendência das respostas públicas à pandemia COVID-19, já que o tinha sido antes na Região Autónoma dos Açores através da Resolução do Conselho do Governo no 123/2020, de 4 de maio, que o determinou para os concelhos de Ponta Delgada, Lagoa, Ribeira Grande e Vila Franca do Campo, da Ilha de São Miguel; Ilhas Terceira, Graciosa, São Jorge, Pico e Faial, até dia 31 de maio. 
precedente antes da declaração do subsequente ${ }^{41}$. Os seus pressupostos estão determinados no no 2, do artigo 9o, do mesmo diploma ${ }^{42}$ e a competência para sua declaração, o seu ato e âmbito material, constam dos artigos 16o e 17o, respetivamente.

Por sua vez, a situação de alerta ${ }^{43}$ está reconhecida na alínea a), do no 1 , do artigo 8, do mesmo diploma. Os seus pressupostos constam do no 1 , do artigo 9o, e a competência para a sua declaração, o seu ato e âmbito material encontram-se nos artigos 13o e 14 o, respetivamente ${ }^{44}$.

Todas estas situações de exceção administrativa, calamidade, contingência e alerta, dadas as especificidades das respostas públicas necessárias perante a crise da pandemia, deverão ser articuladas com as autoridades de saúde, designadamente pela aplicação da lei relativa ao sistema de vigilância em saúde pública ${ }^{45}$ que alarga e intensifica os poderes administrativos das entidades competentes, bem como da restante Legislação COVID-19 aplicável. A graduação de gravidade destas situações de excecionalidade administrativa que se constata na Lei de Bases da Proteção Civil é decrescente, com a situação de calamidade a assumir-se como aquela que exige respostas administrativas mais robustas e a de alerta a que implica respostas mais contidas. Na nossa opinião, as diferenças gradativas entre as situações de contingência e de alerta são pouco significativas - pelo contrário, conforme expusemos, a situação de calamidade corresponde a um estado de quase-emergência

41 Número 3, do artigo \&o, da Lei oㅡ 27/2006, de 3 de julho (com as alteraçôes da Lei no 80/2015, de 3 de agosto): «A declaração de situação de contingência ou de situação de calamidade pressupóe, numa lógica de subsidiariedade, a existência prévia dos atos correspondentes aos patamares precedentes, salvo na ocorrência de fenómenos cuja gravidade e extensão justifiquem e determinem a declaração imediata de um dos patamares superiores».

42 Artigo 9o, no 2: «A situação de contingência pode ser declarada quando, face à ocorrência ou iminência de ocorrência de algum ou alguns dos acontecimentos referidos no artigo 3o, é reconhecida a necessidade de adotar medidas preventivas e ou medidas especiais de reação não mobilizáveis no âmbito municipal.»

43 Recordamos que a situação de alerta tinha sido a primeira resposta governamental quando a pandemia atingiu Portugal, tendo sido declarada em todo o território nacional logo em 13 de março de 2020, pelo Despacho no 3298-B/2020. Demonstrou-se como insuficiente e foi revogada cinco dias depois pelo advento do estado de emergência, decretado através do Decreto do Presidente da República no 14A/2020, de 18 de março.

$44 \mathrm{O}$ âmbito material das situaçóes de alerta e de contingência, que constavam dos artigos 15o e 18o, respetivamente, foram revogados pela lei no $80 / 2015$, de 3 de agosto. O aparente vazio legislativo deverá ser preenchido com as determinações existentes para os regimes de cada uma das situações administrativas excecionais, bem como da interpretação sistemática deste diploma e dos restantes que também se aplicam a estas mesmas situações.

45 Lei no 81/2009, de 21 de agosto. 
já que envolve respostas públicas de envergadura substancial. Essa nossa visão de uma linha de identidade lógica na conceção e consequências administrativas entre as situaçôes de contingência e de alerta substancialmente menores do que as que se verificam no estado de calamidade pode ser comprovada na análise da Resolução do Conselho de Ministros no 51-A/2020, de 26 de junho, designadamente no seu artigo 5o, cujo âmbito de aplicação é a Área Metropolitana de Lisboa, e, sobretudo, no seu artigo 6o, de aplicação circunscrita às freguesias sujeitas a situação de calamidade e cujo conteúdo impositivo e energicamente restritivo o faz aproximar, inapelavelmente, do regime administrativo que vigorou durante o estado de emergência. Ou seja, ao nível das respostas administrativas são bastante maiores as conexôes lógicas entre o estado de emergência, de configuração constitucional, e a situação de calamidade do que entre esta última e as demais situações típicas de necessidade administrativa como são as situações de contingência e de alerta. A consequência relevante para esta nossa reflexão é que os poderes acrescidos que decorrem do princípio da necessidade administrativa subsistirão como pano de fundo e contextualização permanente quer no estado de emergência quer na situação de calamidade, enquanto que apenas poderão ser utilizados incidental e fundamentadamente, caso a caso, nas situaçóes de contingência e de alerta.

\section{DO ESTADO DE NECESSIDADE ADMINISTRATIVO}

O sistema é naturalmente englobante; e o jurídico tende a abarcar nas suas previsóes lógicas e normativas todas as situações factuais juridicamente relevantes, encaminhando os seus efeitos num certo sentido achado como justo pelo próprio sistema. Contudo, independentemente da sua complexidade ou do grau de aperfeiçoamento, todos os sistemas abrem brechas, encontram algo que foge aos seus mecanismos: por vezes por imprevisão, outras intencionalmente visando a criação de "válvulas de escape" aliviantes. O sistema jurídico trata condutas sociais e, estas, são pautadas por uma acentuada repetição e antevisão de comportamentos e resultados que muito relevam na elaboração normativa. Aí, importa, também, a perceção que se deve outorgar a uma grande margem de manobra para determinadas ações e factos para que se possam abranger o maior número possível, ainda que sejam fora do comum. É exatamente nas conjunturas factuais incomuns que o problema oferece 
maiores perplexidades. Concetualmente, "factos incomuns" serão aqueles acontecimentos sociais juridicamente relevantes que pela sua raridade, limitada oportunidade de surgimento na vida social são colocados como situações fora do quotidiano, que são suscetíveis de escapar à possibilidade de tutela rotineira que o sistema comporta - estas serão as conjunturas extraordinárias.

Mas é possível descortinar um outro tipo de situações factuais incomuns que têm o seu acento tónico no sentido lógico da sua expressão factual; i.e. são conjunturas que, independentemente do problema da sua maior ou menor possibilidade de repetição, constituem uma confrontação lógica com a normalidade das situações-tipo, por se direcionarem em sentido contrário da regra factual de onde derivam - aqui, estaremos perante conjunturas excecionais. Julgamos serem estas últimas as que oferecerão maiores problemas para o sistema, dadas as naturais dificuldades de assimilação, e as que resultarão no maior número de atuaçóes administrativas ao abrigo do estado de necessidade. Os vetores deste tipo de atuação deverão ser prioritariamente normativos, mas, sublinhe-se desde já, não se pode aceitar a ideia de uma qualquer forma de inércia da Administração motivada pela natureza incomum das situações que tem de tutelar em concreto. Assim terão de ser encontradas outras formas de solucionar estas questóes, dentro da lógica global do sistema e no respeito pelos fins de interesse público que terão de ser implementados; repita-se quer pela criação normativa, quer por uma atuação jurídica desprovida de parâmetro legal concreto.

Desde há muito, que os juristas compreenderam que ainda que se consiga criar uma ampla variedade de normas que tipifiquem, tanto quanto possível, situaçóes extravagantes e incomuns, nunca se poderá ter a veleidade de tudo prever e normativizar. $\mathrm{E}$, se os mecanismos existentes para este tipo de situações não resolverem o problema restarão, então, os princípios jurídicos produtores da lógica global do sistema que, em conjunto ou singularmente, articularão a solução. As situaçôes extraordinárias, no âmbito dos comportamentos administrativos, muitas vezes não encontram cobertura jurídica e não comportam, também, um tratamento que derive das regras mediante as quais o "direito da normalidade" resolva satisfatoriamente este tipo de questóes. Como as situações exigem uma ação reguladora por parte dos poderes públicos por se reconduzirem a situações de interesse público essencial e prioritário em que a 
intervenção da Administração é exclusiva e indispensável - estaremos, portanto, diante de factos jurídicos que os publicistas doutrinariamente classificam como situações ou estado de necessidade ${ }^{46}$.

O conceito de estado de necessidade lida com delicadas questóes jurídicas que se prendem com a materialização dos fins de interesse público, a obrigação de agir dos entes administrativos e a proteção dos direitos e das garantias dos particulares. E, salvaguardando a lógica intrínseca do princípio da legalidade e da juridicidade, quando as normas não refletem globalmente a factualidade extraordinária existente será precisamente a questão da aplicação normativa que poderá acabar por ser posta em causa. É nesse sentido que interpretamos o conceito moderno do princípio da legalidade, nomeadamente mediante a indispensabilidade de superar as suas incompletudes naturais ou agravadas pelas circunstâncias excecionais. Nas palavras de Mário Aroso de Almeida: «... a circunstância de os órgãos da Administração serem investidos na titularidade de um conjunto heterogéneo de interesses públicos, cuja satisfação é assumida pela comunidade como uma necessidade coletiva que lhes cumpre promover, permite compreender que a atividade administrativa não possa ser uma atividade integralmente subordinada à lei, no sentido de ter de encontrar sempre necessariamente na lei a definição precisa dos termos em que se deve concretizar. Neste ponto radicam as insuficiências do princípio da legalidade administrativa $\gg^{47}$.

O órgão administrativo na hora de atuar, colocado na situação concreta, deve ter parâmetros objetivos de valoração perspetivados normativamente que lhe permitam a graduação do perigo existente e qualificar a conjuntura. Depois, mediante o resultado obtido, exercerá uma conduta proporcional à gravidade encontrada, podendo atuar com poderes extraordinários unicamente na medida em que tal for estritamente imperioso para afastar o perigo e continuar a prossecução do fim público. Uma das

46 Por todos, Gonçalves, cit., pp. 388 e ss. Otero, Paulo (2016). Direito do Procedimento Administrativo. Coimbra: Almedina: 127 ss, Correia, J. M. Sérvulo (2010). "Revisitando o Estado de Necessidade”. In Em Homenagem ao Professor Doutor Diogo Freitas do Amaral, Coimbra: Almedina; Frier (1987). "Lurgence”. In Bibliotheque de Droit Public. Paris: LGDJ: 126 e ss.; Garcia, Alvarez. (1996). El concepto de Necessidad en Derecho Publico, Madrid: Civitas: 155 e ss; Angliolini (1986). Necessità ed Emergenza nel Diritto Pubblico. Padova: Cedam: 96 e ss.

47 Almeida, cit., p. 85. 
maiores dificuldades prende-se com a impossibilidade lógica de determinação legislativa ou regulamentar apriorística dessas circunstâncias factuais possíveis, mas sempre inusitadas e incomuns, ao contrário do que sucede com os fins que a Administração prossegue que estão previamente plasmados e inseridos nas regras do ordenamento jurídico. Na verdade, os órgãos legislativos apenas conseguem fazer uma previsão normativa de algumas - dentro de uma infinidade de possibilidades - daquelas circunstâncias incomuns suscetíveis de colocar em perigo a implementação dos fins de relevante interesse público, relacionando os dois elementos inerentes à necessidade mediante uma norma determinada. Mas, ainda assim, tem-se verificado uma intenção de incremento da tipificação de situaçốes de necessidade no nosso sistema e no direito comparado com o propósito claro de dotar, tanto quanto possível, a atividade administrativa de um maior grau de certeza e segurançą ${ }^{48}$.

Nasceu, desse modo, ao lado do estabelecimento das condições normais de exercício da ação administrativa um regime legal de crise, de emergência, com o duplo objetivo de colocar sob o âmbito da previsão legal o maior número de circunstâncias factuais: quer as de normalidade, quer as excecionais e extraordinárias. No entanto, parece evidente que pelos mecanismos naturais da vida e das mutaçôes sociais este tipo de conjunturas tende sempre a aparecer imprevisivelmente, e sob novas configurações que exigem respostas diversificadas por parte dos poderes públicos, apesar de todos os esforços para as enquadrar normativamente. Assim, mesmo que o sistema tente enquadrar previamente na parte hipotética das normas as eventuais conjunturas de necessidade, sempre existirão vicissitudes e eventos novos, não previstos e que dificilmente serão preenchidos pelas regras normais criadas para resolver este género de situaçóes lacunosas, como o recurso ao raciocínio da analogia como processo de integração no sistema ${ }^{49}$.

48 É nesse contexto que devemos incluir o estado de sítio e o estado de emergência, consagrados no artigo 19o da CRP e a lei no 44/86, de 30 de setembro (Regime do Estado de Sítio e do Estado de Emergência), bem como as disposições pertinentes da Lei de Bases da Proteção Civil, entre outras disposições do nosso ordenamento jurídico que serviram de suporte à decretação da situação de calamidade.

49 Sobre o problema das lacunas e a defesa da possibilidade da aplicação analógica das normas excecionais vistas na sua aceção de jus singulare seguimos Neves, Castanheira (1993). Metodologia Jurídica - Problemas fundamentais, Boletim da Faculdade de Direito da Universidade de Coimbra: 273 e ss. 
E, ainda, que, de acordo com alguma doutrina ${ }^{50}$, se queira aceitar a integração de lacunas por recurso à analogia com plena aplicabilidade às normas excecionais - posição conflituante com a proibição expressa constante no direito português, no artigo 11ำ, do Código Civil - tal não deverá ser permitido no tipo de situaçôes em que o fim de interesse público não for cabalmente atendido na sua íntima relação com a conjuntura factual existente; ou seja, somos de opinião que o raciocínio integrativo da analogia apenas poderá ser utilizado com especiais precauções dadas as peculiares e prioritárias exigências de salvaguarda dos fins públicos em causa. Só que esse "direito da anormalidade" aprioristicamente pensado corresponde a um abrigo legislativo ao qual se irão reconduzir uma série variada de situaçóes de excecionalidade muito diversas. Contudo, pura e simplesmente, não consegue resistir a hipótese de se ir legislando à medida que forem surgindo eventuais situações incomuns para as quais não subsiste qualquer resposta normativa ${ }^{51}$. Não apenas porque o tempo adequado para o surgimento dessa resposta administrativa não se compadece com as inevitáveis morosidades e complexidades do processo legislativo - para além disso, o carácter de excecionalidade dessas circunstâncias factuais implica, na maior parte dos casos, uma celeridade acrescida, uma rapidez de atuação dos poderes públicos que tornam esta hipótese impraticável.

A necessidade, como conceito jurídico, está na base de toda esta discussão sobre a atividade administrativa durante as diferentes etapas constitucionais e administrativas das respostas públicas à pandemia COVID-19. Como parâmetro de condutas dos poderes públicos nessas situações extraordinárias, como princípio regulador e eventualmente derrogador, a necessidade permite o preenchimento de lacunas originárias do direito positivo, bem como, e sobretudo, daquelas que vêm ulteriormente a surgir devido às mutações sofridas pela normalidade previsível dos factos e pela imposição de cumprir o fim de interesse público a desenvolver, possibilitando que diante de uma determinada conjuntura factual exista um meio jurídico adequado e proporcional para a realização desse objetivo público.

50 Por todos, Castanheira Neves, cit.: 274, que refere que o art. 11으, do Código Civil, deve ser interpretado de acordo com o elemento histórico e revela uma «excessiva prudência legislativa» ou, inclusivamente «...a ideia inaceitável de uma como que menoridade da nossa judicatura para solução tão arrojada!».

51 Terá sido precisamente o que sucedeu com o gigantismo da Legislação COVID-19 que quase parece um sistema em autorreprodução sem fim à vista. 
No entanto, só serão juridicamente atendíveis e não sancionáveis pelos órgãos de controlo, designadamente os jurisdicionais, aqueles comportamentos que exercidos em função do estado de necessidade estejam submetidos a certos limites e requisitos, dos quais se salientam os seguintes:

i. A sua imprescindibilidade; efetivamente, só teremos presente o conceito de estado de necessidade em direito administrativo quando a atuação da Administração for indispensável e inadiável para a concreta implementação do fim de relevante interesse público em causa;

ii. A sua adequação teleológica; a conduta administrativa terá de ser feita em função do fim legal e regulamentarmente prosseguido, de acordo com o conteúdo finalístico dos poderes de direito administrativo dos órgãos competentes; iii. O princípio da proporcionalidade; os modos, as formas e os meios de atuação dos órgãos administrativos devem ser os que devida e exclusivamente se adequem ao fim pretendido e aos factos extraordinários que a situação comporta.

Neste seu pleno acolhimento o princípio da proporcionalidade, em consonância plena com o princípio da adequação ${ }^{52}$, agora um princípio jurídico autónomo, resulta numa verdadeira proibição do excesso, aferida em cada caso concreto pelos órgãos competentes e que obriga a Administração, em cada momento, utilizar um meio que represente um menor sacrifício para as posiçóes jurídicas dos particulares ${ }^{53}$, num equilíbrio equitativo com as vantagens adquiridas pela obtenção da realização do fim público perspetivado.

O ordenamento jurídico administrativo português, sublinhamos novamente, prevê e enquadra expressamente esta situação na figura do estado de necessidade, artigo 3o, no 2, do CPA, prefigurando a possibilidade de poderes derrogatórios em certos momentos da sua verificaçãa ${ }^{54}$. O estado de necessidade é, dessa forma, um conceito jurídico com uma clara determinação teleológica. Em face do fim específico pretendido pelos poderes públicos será possível valorar-se o alcance dos factos, constatando-se a maior

52 Cfr. Gonçalves, cit., p. 409.

53 Cfr. Oliveira, Esteves de, Gonçalves, Pedro, Amorim João (1993). Código de Procedimento Administrativo Anotado, Vol. I, Coimbra: Almedina, anotação ao artigo 5o, no 2: 153.

54 Cfr. Gonçalves, cit.: 391. 
ou menor gravidade dos acontecimentos, a proximidade do perigo, componentes desprovidos de qualquer valor absoluto, mas que encontram o seu sentido relativamente ao fim. Estabelecida a relação do elemento fáctico com o fim pretendido deverá observar-se a sua eventual adequação lógica às normas jurídicas positivas - as que integram o direito da normalidade. Se este corpo de regras não abarcar suficientemente a conexão dos factos com o fim, restará aos órgãos administrativos competentes o recurso ao estado da necessidade, enquanto vetor de conduta com um conteúdo e limites encontrados em função do fim que deve ser desenvolvido diante de uma certa conjuntura fáctica anormal que o ameaça.

Por outro lado, o direito da normalidade, não tendo expressão e aplicação cabal neste tipo de situações extraordinárias e excecionais, não poderá, também, obstaculizar a implementação desses fins essenciais para a comunidade, nem nunca poderá servir como pretexto para a inércia dos órgãos administrativos face a essas tarefas, antes pelo contrário. Deverá mesmo constituir um dos principais meios de desenvolvimento e de implementação desses fins e jamais ser utilizado para tornar as ações desses mesmos órgãos inúteis ou ineficazes. Donde se conclui, que quando cumulativamente se verifiquem os requisitos anteriormente enunciados deverão os órgãos administrativos competentes proceder à realização dos fins que lhe estão confiados utilizando os meios idóneos para tal, incluindo os instrumentos jurídicos had hoc que lhe são proporcionados pelo sistema.

\subsection{Poderes de derrogação da lei em face do estado de necessidade}

De entre todos os possíveis efeitos do estado de necessidade administrativo os mais extremados serão aqueles que apresentam de cariz derrogatório, i.e. os que vão afastar as normas de direito positivo que preveem as condutas dos órgãos administrativos naquele tipo de situações mas cuja utilização deixou de oferecer garantias de realização plena do interesse público em questão. $\mathrm{O}$ alcance destes efeitos derrogatórios a estas circunstâncias excecionais através do comportamento dos órgãos administrativos competentes não poderá ter, obviamente, uma extensão ilimitada, mas, pelo contrário, adquirir uma série de demarcações e de reservas de ação que tornem esse afastamento normativo a atividade proporcionada à gravidade e iminência das circunstâncias 
extraordinárias e aos objetivos e fins legalmente definidos para esses órgãos administrativos. Assim, a relatividade intrínseca que caracteriza o conceito de necessidade impossibilita qualquer tentativa de dele oferecer uma definição apriorística de carácter geral. O estado de necessidade deve ser considerado um conceito jurídico indeterminado ${ }^{55}$ cujo conteúdo específico e os efeitos resultantes da sua aplicação só se poderão conhecer a posteriori, após a composição em cada caso concreto dos elementos fácticos e jurídicos que o integram. Esta classificação como conceito jurídico indeterminado tem como principal consequência a possibilidade da atuação administrativa ser objeto de controle jurisdicional, embora limitado pelas nebulosidades existentes na auréola ${ }^{56}$ de imprecisão do conceito, na chamada "zona cinzenta”, onde existe liberdade de ação administrativa devidamente refreada ${ }^{57}$.

\subsubsection{Poderes de derrogação e o perigo concreto para a concretização do fim de interesse público}

Para que estejamos perante um estado de necessidade que possa implicar poderes derrogatórios de normas legais ou regulamentares a conjuntura factual terá de ter como um dos seus componentes principais uma ideia de perigo concreto, inequívoco, para a efetivação de um concreto fim de interesse cometido aos órgãos administrativos competentes $^{58}$. A salvaguarda de um objetivo essencial e a realização de um fim prioritário de interesse público ${ }^{59}$ constitui a verdadeira "pedra de toque" do conceito da necessidade administrativa. Neste ponto, não o consideramos como inserido no elemento teleológico - como pareceria natural - mas, sobretudo, dotado da função de aferir e valorar a situação fáctica como suscetível de produzir o estado de necessidade.

55 Cfr. Gonçalves, op. cit.: 253 e ss.

56 Sobre esta temática seguimos Gonçalves, idem; Correia, Sérvulo (1987). Legalidade e Autonomia Contratual nos Contratos Administrativos. Coimbra: Almedina: 120 e ss., Andrade, J. C. Vieira de (2017). Liçôes de Direito Administrativo, IUC, 5a ed., Coimbra: 54.

57 Por todos, Soares, Rogério (1978) Direito Administrativo (1978), Coimbra: Ed. Policopiada. Enterría, Garcia de, Fernández, Tomaz-Ramon (1996) Curso de Derecho Administrativo, I, 7o ed., Madrid: Civitas: 452-469. 58 Cfr. Gonçalves, cit.: 393-394.

59 Cfr. Andrade, cit.: 49 e ss. 
Teoricamente, é possível identificar diferentes graus de perigo, com reflexos em distintas "escalas" de necessidade, que por vezes surgem com gradações e delimitações entre si extremamente subtis (e outras parecem ser pura e simplesmente iguais), quando não intrincadas e sinuosas, nas suas denominações normativas: situações urgentes, situaçóes de circunstâncias excecionais, de extraordinária necessidade, de extraordinária e urgente necessidade, de força maior ${ }^{60}$. Quanto a nós, o perigo terá de existir no seu sentido próprio e a todo o tempo da conduta administrativa ao abrigo da necessidade, i.e. tem de existir uma coincidência temporal entre o surgimento e manutenção dos factos extraordinários, anormais e imprevistos, suscetíveis de resultar em perigo para um determinado fim público e a atividade da Administração que vai ser desenvolvida para o obviar. Neste contexto, a situação de perigo e o consequente comportamento dos órgãos públicos têm de ser contemporâneos; e extinto o perigo desaparece imediatamente a necessidade, donde resultará a total impossibilidade de atuação dos órgãos administrativos através deste princípio.

$\mathrm{Na}$ delimitação do conceito de perigo em direito administrativo importa relevar alguns fatores que permitam aferir, inquestionavelmente, a sua presença real. Assim, diante de uma conjuntura factual extraordinária será imperioso:

i. Estabelecer um nexo de causalidade eventual, através de um juízo de prognose, sobre os efeitos futuros da inércia ou de uma insuficiente ação dos órgãos administrativos face às circunstâncias concretas da anormalidade factual;

ii. Efetuada essa relação de acentuada probabilidade de causa-efeitos, estes últimos deverão ser potencialmente danosos ou, até, impeditivos da implementação do fim público em causa;

iii. A atuação ao abrigo do princípio da necessidade deverá surgir como o único meio, eivado de juridicidade, de se conseguir a realização do escopo público imputado legalmente aos órgãos administrativos competentes e que se encontra ameaçado pela natureza singular e extraordinária dos eventos.

A questão fundamental é que esta presença de perigo concreto para a concretização

60 Angiolini, cit.: 116 e ss. Frier, L'urgence, cit., pp. 144 ss. Garcia, cit.: 250; Agirreazkenaga, I., La coaccion Administrativa Directa (1990). Madrid: Civitas: 329 ss. 
do interesse público pode justificar que através da necessidade esses órgãos competentes possam exercer condutas praeter legem - e, mesmo, contra legem - com eventuais efeitos derrogatórios ou suspensivos do direito da normalidade.

\subsubsection{Estado de necessidade administrativo e urgência}

Por último, não gostaríamos de deixar de abordar uma das questóes que mais turbulentas na temática da necessidade e que se prende com a separação, ao nível legal e jurisprudencial, entre os conceitos de urgência e de necessidade.

A urgência ${ }^{61}$ não se confunde com necessidade embora nela esteja ínsita concetualmente ${ }^{62}$. A urgência é uma vertente da necessidade: não há urgência sem estarem presentes todas as componentes desta. Mas, a inversa não é verdadeira: i.e. uma conduta ao abrigo da necessidade não será automaticamente urgente. Tal só sucederá se a acompanhar a necessidade - conceito tipo - exista, também, a obrigação de o fazer com rapidez, dada a iminência da ameaça para o fim público. $O$ fator temporal da atuação administrativa constitui o cerne da distinção das duas figuras ${ }^{63}$. Donde, a urgência pode ser definida como toda a conduta sob o parâmetro da necessidade cumulada com a premência de atuar imediatamente ou num curto espaço de tempo ${ }^{64}$.

61 Acerca das características dos atos urgentes, Andrade, Vieira de (1991). O Dever de Fundamentação Expresso de Actos Administrativos, Coimbra: Almedina: 148 e ss. Oliveira, et al, cit.: 401.

62 A maioria da doutrina defende uma radical distinção entre os dois conceitos, uma "destrinça"; por todos, Amaral, Freitas do, Garcia, Maria da Glória Dias (1999). "O Estado de Necessidade e a Urgência em Direito Administrativo", in Revista da Ordem dos Advogados, ano 59, Lisboa: 455.

63 A destrinça contém analogias com a distinção entre princípios da prevenção e o da precaução em direito do ambiente, sendo que este integra o conceito daquele. O princípio da precaução potência a utilização de respostas administrativas de força acrescida em face de riscos e ameaças iminentes ou já em desenvolvimento - ver GOMES, Carla Amado (2018). Introdução ao Direito do Ambiente, 4a (2019). Droit de L'environnement (8 a ed.), Paris: Dalloz: 140 ss., Cutanda, Blanca Lozano, Candeira, Alejandro Lago, Álvarez, Luis Felipe Lopez (2014). Tratado de Derecho Ambiental, Madrid: CEF: 126 ss., Barroso, Borja Sánchez (2019). "El Princípio de Precaución Y Su Posible Contribuición para Alcanzar los Objetivos de Desarrollo Sostenible de la Agenda 2030" in Principios de Derecho Ambiental Y Agenda 2030, Valencia: tirant lo blanch: 124 ss., Frade, Marlene (2020), O Princípio da Precaução no Direito do Ambiente, Lisboa: AAFDL. 64 Cfr. Gonçalves, cit.: 395-396. 
$\mathrm{Na}$ verdade, este é um aspeto da maior relevância, pois, independentemente da verificação em concreto da situação de necessidade em todos os elementos, a sua adição com a imperiosa obrigação de atuar imediatamente ou num curto espaço temporal, caso contrário seria esgotado o fim de interesse público relevante - de acordo com a tradicional ideia do periculum in mora -, vem colocar o problema em moldes distintos. E, como já foi anteriormente aludido, o nosso ordenamento jurídico administrativo reconhece claramente esta excecionalidade, quer no já referido artigo 3o, no 2, do CPA, quer, ainda, no artigo 161oㅡㄴ no 2, alínea 1), do mesmo Código, que permite a validação nos casos em que a Administração pratica um ato administrativo em estado de necessidade com preterição total do procedimento administrativo legalmente exigido ${ }^{65}$.

Queremos significar que é assaz diferente ter de agir em estado de necessidade e ser obrigado a fazê-lo de imediato ou com grande rapidez. E que essa diferença poderá redundar:

i. No emprego por parte dos órgãos administrativos de meios distintos para salvaguardar o mesmo fim público;

ii. E que entre esses meios eventuais estarão presentes, de uma forma acrescida, os efeitos suspensivos e - em certas situações mais extremas - derrogatórios de normas do "direito da normalidade".

Assim, uma atuação administrativa ao abrigo da urgência traduz-se numa possibilidade de aumento dos poderes concretos de ação, mantendo-se vigentes todos aqueles que derivam da necessidade e podendo o órgão atuante escolher a todo o tempo, através de um juízo discricionário e mediante a valoração que faz à situação que lhe subjaz, as medidas mais indicadas para cumprir o fim que tem à sua cura. A urgência será sempre um suplemento de poderes administrativos para quem atua, um aumento do seu campo de atuação e uma reflexa possibilidade de se afastarem, naquela situação concreta, regras jurídicas virtualmente aplicáveis.

65 Cfr. Gonçalves, cit.: 390. 
Assim, em situação de urgência os órgãos administrativos, além de poderes excecionais para salvaguardar os seus fins, devem atuar imediatamente ou com suficiente rapidez visando afastar a possibilidade de dano. Esta tarefa deverá ser exercida, preferentemente, antes da materialização da ameaça de perigo, urgência preventiva ${ }^{66}$.

66 A urgência, em certas situações, poderá também existir depois da verificação do dano, visando a possível resolução do problema ou impedir o alastramento do mal já iniciado - será a urgência reparadora. 